\title{
Imepitoin Shows Benzodiazepine-Like Effects in Models of Anxiety
}

\author{
Odilo Engel1*, Aleksandar Masic ${ }^{2}$, Gary Landsberg ${ }^{2}$, Melissa Brooks ${ }^{2}$, Daniel S. Mills ${ }^{3}$ \\ and Chris Rundfeldt ${ }^{4,5}$
}

\begin{abstract}
${ }^{1}$ Boehringer Ingelheim Vetmedica GmbH, Ingelheim am Rhein, Germany, ${ }^{2}$ CanCog Technologies Inc., Toronto, ON, Canada, ${ }^{3}$ Animal Behaviour, Cognition and Welfare Group, School of Life Sciences, University of Lincoln, Lincoln, United Kingdom, ${ }^{4}$ Drug Consulting Network, Coswig, Germany, ${ }^{5}$ Department of Pharmacology, Toxicology and Pharmacy, University of Veterinary Medicine Hannover, Hanover, Germany
\end{abstract}

OPEN ACCESS

Edited by: George Panagis, University of Crete, Greece

Reviewed by: Karolina Pytka, Jagiellonian University, Poland Elif Engin,

McLean Hospital, United States

*Correspondence: Odilo Engel odilo.enge/@boehringeringelheim.com

Specialty section:

This article was submitted to

Neuropharmacology,

a section of the journal

Frontiers in Pharmacology

Received: 21 June 2018 Accepted: 08 October 2018

Published: 01 November 2018

Citation:

Engel O, Masic A, Landsberg G, Brooks M, Mills DS and Rundfeldt C

(2018) Imepitoin Shows Benzodiazepine-Like Effects in Models of Anxiety.

Front. Pharmacol. 9:1225. doi: 10.3389/fphar.2018.01225
Imepitoin is a low affinity partial agonist for the benzodiazepine binding site of $\gamma$-aminobutyric acid $\left(\mathrm{GABA}_{\mathrm{A}}\right)$ receptors, and is currently used as an antiepileptic in dogs. Here we tested imepitoin for anxiolytic properties. In an in vitro model, imepitoin was capable of preventing the effect of corticotrophin releasing factor (CRF) on locus coeruleus neurons without suppressing the basal activity of these cells, an activity which is suggestive for an anti-stress effect of imepitoin. In addition, we applied a battery of standard rodent preclinical tests for anxiety behavior including elevated plus mazes in mice and rats, light-dark-box in mice and rats, social interaction test in rats, or the Vogel conflict test in rats. In all models, the observed profile of imepitoin appeared similar to benzodiazepines and typical for anxiolytic drugs. We also observed anxiolytic activity in dogs in a provoked open field sound-induced fear model, where reactions to noises were elicited by a sound recording of thunderstorms. Imepitoin caused an increase in locomotion measured in distance traveled and an ameliorating effect on cortisol levels in response to thunderstorm noises. For comparison, dexmedetomidine caused a decrease in locomotion and had no effect on cortisol. In all animal models the doses needed for an anxiolytic effect were not associated with sedation. In rodents, there was at least a factor of 10 between anxiolytic doses and doses with mild signs of sedation. In summary, imepitoin showed similar anxiolytic activities as benzodiazepines but without producing the known adverse reactions of benzodiazepines such as sedation.

Keywords: anxiolytic, imepitoin, in vitro, in vivo, dog, mouse, rat

\section{INTRODUCTION}

Physiologically, anxiety is an important protective mechanism to increase vigilance, which allows an individual to react to a perceived present or anticipated threat with an appropriate behavior (e.g., flight). When occurring at inappropriate times or to an excessive degree, anxiety can be described as pathological both in humans and in animals (Stein and Steckler, 2010). Despite the high prevalence of these conditions current treatment options are limited (Griebel and Holmes, 2013).

Abbreviations: SD, standard deviation. 
Since full agonist benzodiazepines are known to be potent anxiolytics, it was hypothesized that partial agonists could also potentially retain anxiolytic activity, but without producing the known adverse reactions of benzodiazepines such as sedation, muscle relaxation, and, upon repeated administration, development of tolerance. (Skolnick, 2012).

Imepitoin is a centrally acting drug and a low affinity partial agonist for the BZD binding site of $\gamma$-aminobutyric acid $\left(\mathrm{GABA}_{\mathrm{A}}\right)$ receptors (Rundfeldt and Loscher, 2014). The compound potentiates the amplitude of GABA evoked chloride (Cl-) currents by acting at the $\mathrm{BZD}$ recognition site of the $\mathrm{GABA}_{\mathrm{A}}$ receptor, creating a higher affinity between GABA and its receptor sites. Imepitoin has a lower affinity for the BZD binding site of $\mathrm{GABA}_{\mathrm{A}}$ receptors than $\mathrm{BZD}$ receptor agonists such as diazepam (DZP). Additionally it exhibits a weak calcium $\left(\mathrm{Ca}^{2 \pm}\right)$ channel blocking effect. Currently imepitoin is in veterinary use for the treatment of idiopathic epilepsy in dogs (Rundfeldt and Loscher, 2014).

Anxiolytic effects in the GABA-ergic pathway are mediated by $\alpha 2$ - and $\alpha 5$ and possibly a3- subunit containing $\mathrm{GABA}_{\mathrm{A}}$ receptors (Löw et al., 2000; Whiting, 2006). Previous work demonstrated that imepitoin is active on these receptor subtypes (Sigel et al., 1998).

Here we report results from preclinical studies examining anxiolytic effects of imepitoin. Based on imepitoin's mode of action, we examine whether imepitoin had similar effects as benzodiazepines in commonly used models.

\section{MATERIALS AND METHODS}

\section{Locus Coeruleus (LC) Neuronal Cell Culture}

Single locus coeruleus (LC) neurons in $200 \mu \mathrm{m}$ thick brainstem slices were visualized with infrared videomicroscopy and patch-clamped in the whole-cell configuration as described elsewhere (Liss et al., 1999). These cells exhibit a spontaneous pace maker activity which can be reversibly potentiated with corticotrophin releasing factor (CRF). Drugs were directly applied onto the brain slices in concentrations of $0.1,1$, and $10 \mu \mathrm{M}$.

\section{Animals}

All experiments were carried out in accordance with the principles of the Basel Declaration and according to applicable legislation [i.e., for example European directive on the protection of animals used for scientific purposes (2010/63/EU)]. If applicable, they were approved by the relevant authorities or Institutional Animal Care and Use Committees (IACUC).

Wistar rats (Crl WI BR, 270-330 g), CD rats (Crl 240-325 g) or Crl:NMRI BR mice (25-35 g) were used in the rodent experiments. Standard food (e.g., SNIFF Spezialdiäten GmbH, Soest, Germany) and water were provided ad libitum, and animals were housed in groups under a $12 \mathrm{~h}$ light and dark cycle.

Beagle dogs (Vivocore Inc., Fergus, ON, Canada) were group housed in pens of four with a hide box, a raised resting platform, various toys and background music ( $<85$ decibels). A standard commercial diet once a day and water ad libitum was offered, and $12 \mathrm{~h}$ light and dark cycle was maintained.

The experimental setups were cleaned after each test (e.g., wiped with alcohol).

\section{Drug Preparation and Administration}

For intraperitoneal and oral administration in rodents, all test substances were suspended in 5-hydroxyethylcellulose $(0.5 \%$ in water), with plain 5-hydroxyethylcellulose ( $0.5 \%$ in water) solution serving as placebo. Presumably non-sedative doses for benzodiazepines were chosen, in consideration of the low oral bioavailability of benzodiazepines in rodents compared to humans and other species. In the dog study, tablets identical to the commercial presentation (Pexion ${ }^{\text {TM}}$; Boehringer Ingelheim Vetmedica GmbH, Ingelheim, Germany) were used, and baseline observations under no treatment were used as control. Administration of a single oral dose (20 mg/kg imepitoin) to dogs was performed $138 \mathrm{~min}$ before noise exposure, i.e., to achieve maximum plasma concentrations during the noise exposure (Rundfeldt et al., 2014). Dexmedetomidine as oromucosal gel (Sileo $^{\mathrm{TM}}$; Orion Pharma, Espoo, Finland) was administered $60 \mathrm{~min}$ before testing at a dose of $125 \mu \mathrm{g} / \mathrm{m}^{2}$ according to the manufacturer's instructions.

\section{Elevated Maze in Rodents}

For rats, the maze consisted of three open $(35 \times 10 \mathrm{~cm})$ and three closed $(35 \times 10 \times 15 \mathrm{~cm})$ arms extending from a central platform. In mice, the maze consisted of two open $(17.5 \times 7.8 \mathrm{~cm})$ and two closed $(19 \times 8 \times 15 \mathrm{~cm})$ arms extending from a central platform, placed $80 \mathrm{~cm}$ off floor (Walf and Frye, 2007).

In both cases, adaptation to the test room was ensured by $24 \mathrm{~h}$ housing in the test room and experiments were conducted under controlled light conditions ( $12 \mathrm{~h}$ on: $12 \mathrm{~h}$ off light dark cycle; lights on at $07.00 \mathrm{~h}$, with normal ambient light). The movements of the animals were recorded for 5 min with a video camera for subsequent analysis. The number of entries in the open arms, the number of entries in the closed arms and the time spent in the open arms were measured (Walf and Frye, 2007).

Doses of imepitoin (1-30 $\mathrm{mg} / \mathrm{kg}$ i.p.), alongside the benzodiazepines diazepam $(0.25-2.0 \mathrm{mg} / \mathrm{kg})$, triazolam $(0.003-1.0 \mathrm{mg} / \mathrm{kg})$, and alprazolam $(0.1-1.0 \mathrm{mg} / \mathrm{kg})$, administered $30 \mathrm{~min}$ before test, and pentetrazol (10.0 and $20.0 \mathrm{mg} / \mathrm{kg}$ ) administered $5 \mathrm{~min}$ before test, were given to ten rats per group. In mice ( $n=10$ per group) i.p. doses of imepitoin (doses from 3.13 to $200 \mathrm{mg} / \mathrm{kg}$ ), were compared to diazepam $(0.2-12.5 \mathrm{mg} / \mathrm{kg})$ and placebo administered $30 \mathrm{~min}$ before the test and p.o. administration of imepitoin $30 \mathrm{mg} / \mathrm{kg} 2 \mathrm{~h}$ before testing.

\section{Light-Dark-Box in Rodents}

A two compartment box (each compartment $22 \times 22 \times 22 \mathrm{~cm}$ ) was used in this test, with one light and open and the other dark and closed. Both compartments were connected with an open door. Animals were placed in the light part and observed for $5 \mathrm{~min}$. Latency to first cross in the dark part, total time spent in light part and the number of crosses from one part into the other was measured (Bourin and Hascoet, 2003). Along with a 
placebo group, imepitoin was tested at different doses between 1 and $30 \mathrm{mg} / \mathrm{kg}$ and diazepam at doses between 1 and $10 \mathrm{mg} / \mathrm{kg}$ and placebo ( $n=10$ per group).

\section{Social Interaction Test in Rats}

A pair of rats that were unfamiliar to each other was placed into an arena, one animal at each end (File and Hyde, 1978). Both rats were treated with the same test substance and dose. The arena was a circular open field apparatus made of white plastic, approximately $1 \mathrm{~m}$ in diameter enclosed by $25 \mathrm{~cm}$ high walls. It was covered by a muslin cloth and illuminated with ambient light. Behavior was scored at $15 \mathrm{~s}$ intervals over a $10 \mathrm{~min}$ period. The score values were 0 (No interaction), 1 (Passive interaction, e.g., lying in contact), 2 (one-way investigative interaction, e.g., 1 rat following or sniffing the other), 3 (one-way active interaction, e.g., 1 rat grooming the other), 4 (two-way investigative interaction, e.g., both rats mutually rat following or sniffing the other), or 5 (two-way active interaction, e.g., both rats grooming the other, playing together, etc.). The test was performed in five groups with nine pairs each with imepitoin (doses 3, 10, and $30 \mathrm{mg} / \mathrm{kg}$ ), diazepam (5 mg/kg), and placebo.

\section{Conflict-Based Tests in Rodents}

The Geller conflict test was performed as described elsewhere (Geller and Seifter, 1960). Rats were trained in a standard Skinner box $(23 \times 21 \times 18 \mathrm{~cm}$; MED Associates $)$ that lever-pressing results in a food reward (food pellets $45 \mathrm{mg}$ ). The lever was located on the right of the food pellet dispenser, and above a white and a red signal light were installed. For further training and test, periods of responding by lever pressing to get food pellets on a variable interval schedule (mean value $15 \mathrm{~s}$ ) indicated by a white light are interrupted by periods where, in the presence of a red signal light, food can be obtained more frequently (mean value $10 \mathrm{~s})$ but accompanied by mild footshocks $(0.4 \mathrm{~mA}, 0.5 \mathrm{~s})$. Each lever pressing under white light (i.e., without electric shock) was defined as unpunished response, while those under red light were punished responses. The number of unpunished and punished responses was measured. Groups of eight rats received either imepitoin (3-30 mg/kg), diazepam (16 mg/kg), chlordiazepoxid $(16 \mathrm{mg} / \mathrm{kg})$, or placebo.

Briefly, the Vogel conflict test (Millan and Brocco, 2003) consisted of a Plexiglas conflict test box $(30 \times 23 \times 19 \mathrm{~cm})$. A water bottle was placed outside the box, with a stainless steel spout extending into the box about $2 \mathrm{~cm}$ above floor level. After an unpunished training session of $10 \mathrm{~min}$, the second session lasted $3 \mathrm{~min}$ and was performed on the next day. In that session drinking was punished for 2-s periods, followed by $3 \mathrm{~s}$ unpunished periods. The number of electric shocks $(0.5 \mathrm{~mA})$ received within the $3 \mathrm{~min}$ test period was recorded. Groups of 12 rats received either imepitoin (1-50 mg/kg), diazepam (0.3-30 mg/kg), or placebo.

The four-plate apparatus used in mice is a rectangular chamber $(23 \times 18 \times 30 \mathrm{~cm})$ whose floor is divided into four equally sized rectangular copper plates, as described elsewhere (Jones et al., 1994). The test was divided into two parts, $20 \mathrm{~s}$ of free exploration, followed by a second phase in which each crossing between the plates was punished with a mild $(1.0 \mathrm{~mA})$ and brief
(0.1 s) electric shock to the feet administered by the experimenter using a hand held button. The measure was the number of shocks received in $1 \mathrm{~min}$ period. Groups of 10 mice received either imepitoin (3.13-200 mg/kg), diazepam (0.2-12.5 mg/kg), or placebo.

\section{Noise-Induced Model of Fear and Anxiety in Dogs}

For this test, subjects were placed in an open field arena, which is a room $2.45 \times 2.75 \mathrm{~m}$ for $9 \mathrm{~min}$ (Araujo et al., 2013). It was hypothesized that if a drug has anxiolytic properties then it should result in a shift from fearful flight to behavioral inhibition or non-anxious "rumination" (McNaughton and Gray, 2000) and an increase in exploratory behavior. This would be manifest as an increase in behavioral pauses, but an increase in behavioral activity (since exploratory behavior is more elaborate than flight behavior), without an increase in cortisol in cortisol reactive subjects (raised cortisol being indicative of increased arousal associated with fear response in this context). Animal behavior was recorded via video and distance traveled, as well as frequency and duration of inactivity (defined as the animal sitting or lying down, or not exhibiting any overt behavior) were measured using Ethovision XT (Noldus Information Technology, Netherlands). Blood samples for cortisol measurements were collected $1 \mathrm{~h}$ before and $5 \mathrm{~min}$ after the test.

For training, each subject was allowed to freely explore the room over a 9-min period during which no stimuli were provided. For baseline and test measurements, a thunder track played over a stereo system with a decibel range of 61-85 $\mathrm{db}$ for 3 min of the 9 min period (minutes 4-6).

Beagle dogs (both gender, age 1-6 years) were first grouped based on their cortisol response into cortisol responders (at least a $9 \%$ increase in blood cortisol from the baseline) and non-responders, and secondly on their activity responses as hyperactive responders $(\geq 10 \%$ increase in activity ratio between minutes $1-3$ and minutes 4-6 from training to baseline thunderstorm) and hypoactive responders ( $<10 \%$ increase). In two independent experiments, 24 dogs received imepitoin and 25 dogs dexmedetomidine. Baseline values from the respective experiment values served as control. Drugs were administered as a single dose before the test (imepitoin $135 \mathrm{~min}$, dexmedetomidine $60 \mathrm{~min}$ before thunder test).

\section{Statistics}

Treatment allocation was performed randomly and remained completely blinded for the examiners. Data are presented descriptively as mean and SD, or for ordinal values as median. Hypothesis tests were always performed against placebo control or baseline, using appropriate 2-sided statistical tests for significant differences $(p<0.05$; mainly Mann-Whitney $U$ or $t$-Test for two groups, Dunnett's procedure for more than two groups).

For logistical reasons, most of the animal tests were set up as a series of experiments. A control group was included in each single experiment, and wherever possible, all doses of a test product were tested in the same experiment. 


\section{RESULTS}

\section{Effect on Basal and CRF-Induced Activity in the Locus Coeruleus (LC) Neurons}

The in vitro study indicated that imepitoin (at doses of 1 and $10 \mu \mathrm{M}$ ) acts to decrease neuronal activity induced by CRF but not the basal (spontaneous pacemaker) activity in mouse LC neurons. The half-maximal inhibition could be determined to $60 \mathrm{nM}$ for diazepam and $520 \mathrm{nM}$ for imepitoin, respectively (Figure 1).

\section{Elevated Maze in Rodents}

The influence of imepitoin on anxiety related behavior of rats ( $n=10$ per group) was investigated in an elevated maze. At doses of 10 and $30 \mathrm{mg} / \mathrm{kg}$ i.p. (administered $30 \mathrm{~min}$ before test) the percentage of entries in the open arms and the percentage of time spent in the open arms were significantly increased compared to placebo. The doses 1 and $3 \mathrm{mg} / \mathrm{kg}$ i.p. did not show significant differences to placebo (Figure 2A, Table 1, and Supplementary Table 1).

For comparison the benzodiazepines diazepam $(0.25,0.5$, 1.0 , and $2.0 \mathrm{mg} / \mathrm{kg})$, triazolam $(0.003,0.01,0.03,0.1,0.3$, and $1.0 \mathrm{mg} / \mathrm{kg})$, and alprazolam $(0.1,0.3$, and $1.0 \mathrm{mg} / \mathrm{kg})$ were tested (all i.p. administered 30 min before test). Diazepam significantly increased the percentage of time spent in the open arms (Table 1) at doses of 1 and $2 \mathrm{mg} / \mathrm{kg}$ compared to placebo. For triazolam the percentage of entries was significantly increased for doses of $0.03 \mathrm{mg} / \mathrm{kg}$ and above (Table 1), and the time spent in the open arm was significantly increased for 0.03 and $0.1 \mathrm{mg} / \mathrm{kg}$, while in higher doses sedative effects were observed. Alprazolam significantly increased the percentage of time spent in the open arms at $0.3 \mathrm{mg} / \mathrm{kg}$ (Table 1), while there were sedative effects at the high dose.

In contrast the anxiogenic compound pentetrazol (10.0/20.0 $\mathrm{mg} / \mathrm{kg}$ administered $5 \mathrm{~min}$ before test) was tested. The higher dose decreased the percentage of time spent in the open arms compared to placebo (Table 1).

In mice ( $n=10$ per group) the elevated maze model was used with various i.p. doses of imepitoin $(3.13,6.25,12.5,25,50$, 100 , and $200 \mathrm{mg} / \mathrm{kg})$, diazepam $(0.2,0.39,0.78,1.56,3.13,6.25$, and $12.5 \mathrm{mg} / \mathrm{kg}$ ), and placebo administered $30 \mathrm{~min}$ before the test. After low dose i.p. administration of imepitoin $(3.13 \mathrm{mg} / \mathrm{kg})$ we observed an increased number of entries into the open arm (Table 1). All other variables and doses did not reveal significant treatment effects (Supplementary Table 1). In the highest administered doses of imepitoin (100 and $200 \mathrm{mg} / \mathrm{kg}$ ) slight locomotor sedation was observed in mice. Diazepam increased the number of entries into the open arm with a minimal effective dose of $0.39 \mathrm{mg} / \mathrm{kg}$ (Table 1). At high doses of diazepam $(\geq 6.25 \mathrm{mg} / \mathrm{kg})$ there were indications of sedative effects. At doses

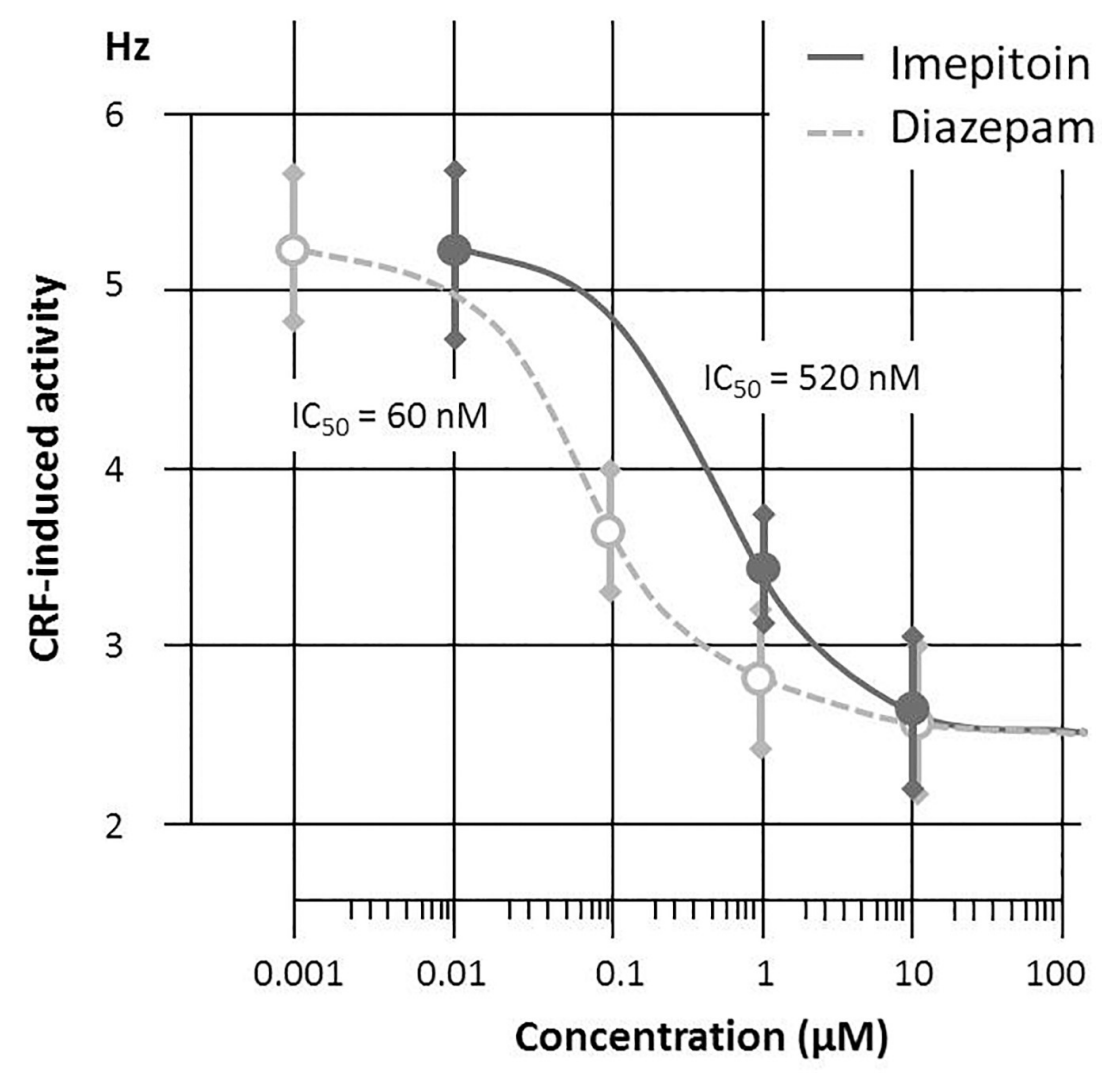

FIGURE 1 | Corticotrophin Releasing Factor (CRF, 200 nM) induced discharge of mouse locus coeruleus neurons are reduced by both Diazepam (doses 0.1 ; 1 and $10 \mu \mathrm{M})$ and imepitoin (doses 1 and $10 \mu \mathrm{M}$ ) with a half maximal inhibition in the range of 60 and $520 \mathrm{nM}$, respectively $(n=3$ per concentration). 


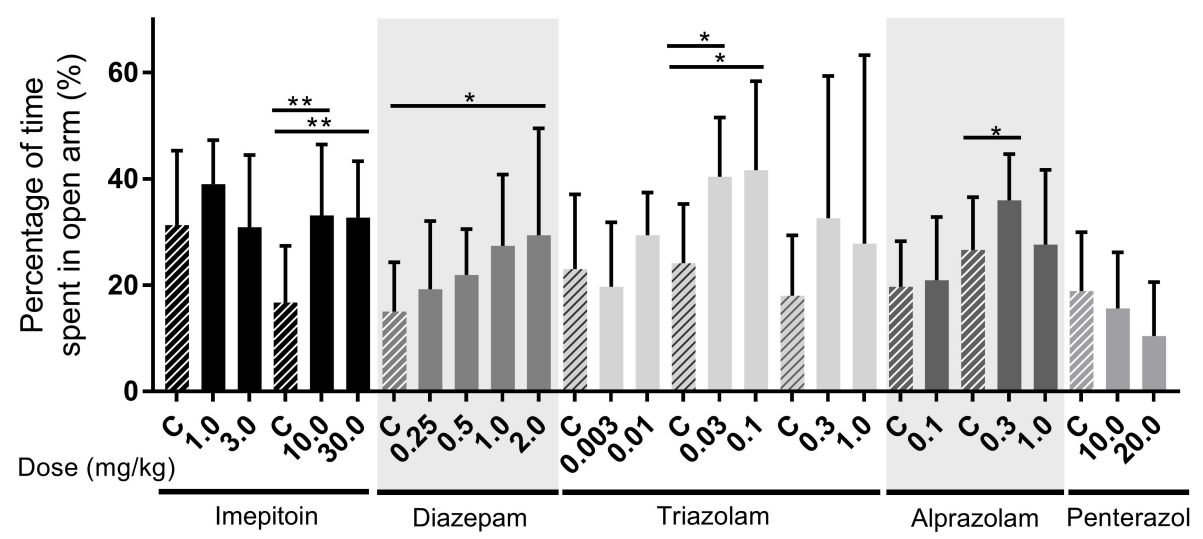

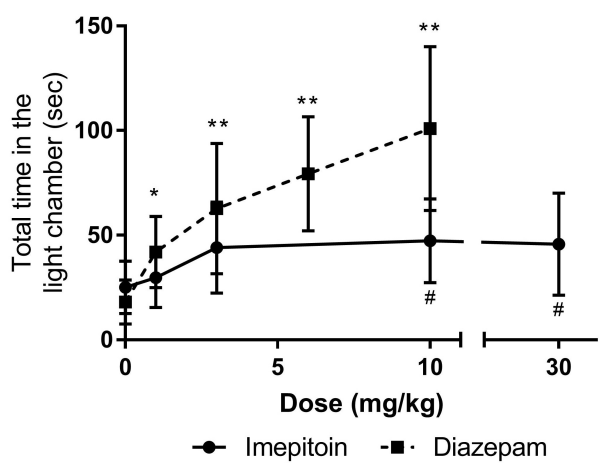

C

Light-Dark-Box (mouse)

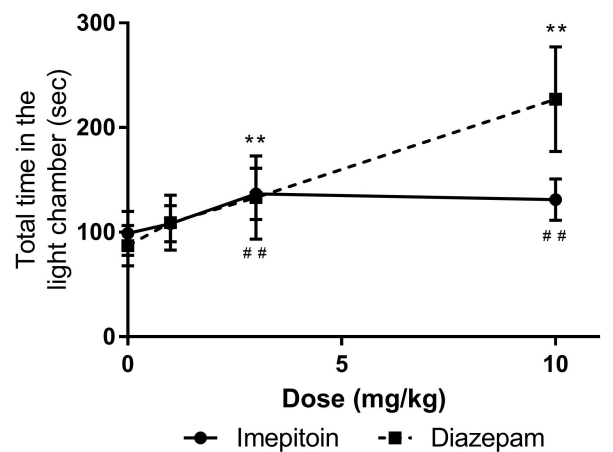

FIGURE 2 | (A) Imepitoin at doses of 10.0 and $30.0 \mathrm{mg} / \mathrm{kg}$ shows significantly increased percentage of time spent in the open arm of the elevated maze in rats compared to placebo control (marked as "C"). Similar effects were observed with different benzodiazepines, and the anxiogenic substance penterazol led to a decreased percentage. (Series of 9 experiments, $n=10$ per group) (B) In rats, the total amount of time spent in the light part of the light-dark-box was significantly increased in doses above $1.0 \mathrm{mg} / \mathrm{kg}$ imepitoin compared to control (0 mg/kg) (Series of three experiments, $n=10$ per group) (C) A similar effect was observed in the light-dark-box in mice (Series of four experiments, $n=10$ per group). For all displays: mean \pm SD; comparison against respective control using ANOVA with Dunnett's post hoc. * or \# $p<0.05$; ** or \#\# $p<0.01$; and the symbol "\#" indicates imepitoin and "*" indicates diazepam.

of $3.13 \mathrm{mg} / \mathrm{kg}$ and $6.25 \mathrm{mg} / \mathrm{kg}$ diazepam, a small number of animals fell off the maze (data not shown).

In mice, after p.o. administration of $30 \mathrm{mg} / \mathrm{kg}$ imepitoin $2 \mathrm{~h}$ prior to the test no effect was observed compared to placebo.

\section{Light-Dark-Box in Rodents}

The effect on the latency to the first cross to the dark part of the box, the total amount of time spent in the light part and the number of crosses were assessed.

In rats ( $n=10$ per group) imepitoin was tested in a dose range of $1,3,10$, and $30 \mathrm{mg} / \mathrm{kg}$ po compared to placebo (administered $2 \mathrm{~h}$ before test). The latency to first cross and total time in the light chamber were significantly increased at doses higher than $1 \mathrm{mg} / \mathrm{kg}$ imepitoin (Table 1), however, no clear dose dependence was observed. The number of movements between the compartments was not significantly increased. No visible side effects occurred within the dose range tested. For comparison, diazepam $(1,3,6$, and $10 \mathrm{mg} / \mathrm{kg}$ oral, $30 \mathrm{~min}$ before test) showed a strong anti-anxiety response in a dose-dependent manner (Figure 2B; parameters with significant effects: latency to the first cross, total time in the light chamber, number of crosses).

In mice ( $n=10$ per group), imepitoin at i.p. doses of 3 and $10 \mathrm{mg} / \mathrm{kg}$ (administered $30 \mathrm{~min}$ before test) significantly prolonged the phases of staying in the light part of the two chamber box in mice compared to placebo. The dose $10 \mathrm{mg} / \mathrm{kg}$ additionally prolonged the latency before the mice entered for first time the dark compartment. The dose $1 \mathrm{mg} / \mathrm{kg}$ showed no changes compared to placebo. Diazepam (1, 3, and $10 \mathrm{mg} / \mathrm{kg}$ ) exerted its anxiolytic like activity in a dose dependent manner (Figure 2C and Table 1).

\section{Social Interaction Test in Rats}

The effect on social interaction was assessed in pairs of unfamiliar rats (5 groups with 9 pairs each) in unfamiliar surroundings under high illumination. Imepitoin administered by oral gavage once daily for four consecutive days, significantly increased social 
TABLE 1 | Results of model studies in rats and mice.

\begin{tabular}{|c|c|c|c|c|c|c|c|}
\hline Treatment & Dose & Measure & Statistical result & Treatment & Dose & Measure & Statistical result \\
\hline \multirow[t]{3}{*}{ Imepitoin } & C & $31.3 \pm 14.0$ & $F(2,27)=1.379$ & Triazolam & C & $24.1 \pm 11.19$ & $F(2,27)=5.392^{*}$ \\
\hline & 3.0 & $30.9 \pm 13.57$ & (ns) & & 0.1 & $41.6 \pm 16.79$ & $p<0.05$ \\
\hline & C & $16.7 \pm 10.69$ & $F(2,27)=6.493^{*}$ & & C & $18.0 \pm 11.35$ & $F(2,27)=0.790$ \\
\hline \multirow[t]{5}{*}{ Diazepam } & C & $15.0 \pm 9.3$ & $F(4,45)=2,633^{*}$ & Alprazolam & C & $19.7 \pm 8.57$ & [seefootnote] \\
\hline & 0.25 & $19.2 \pm 12.84$ & ns & & 0.1 & $20.9 \pm 11.89$ & ns \\
\hline & 0.5 & $21.9 \pm 8.66$ & ns & & C & $26.6 \pm 9.96$ & $F(2,27)=3.884^{*}$ \\
\hline & 1.0 & $27.4 \pm 13.41$ & ns & & 0.3 & $35.97 \pm 8.7$ & $p<0.05$ \\
\hline & 2.0 & $29.4 \pm 20.08$ & $p<0.05$ & & 1.0 & $27.6 \pm 14.07$ & ns \\
\hline
\end{tabular}

Elevated Maze in Mice. Parameter: Entries into open arms. Statistical Test: Dunnett's procedure. $N=10$ per group.

\begin{tabular}{|c|c|c|c|c|c|c|c|}
\hline \multirow[t]{6}{*}{ Imepitoin } & C & $9,8 \pm 3,79$ & $F(7,72)=2.52^{*}$ & Diazepam & C & $9 \pm 2,53$ & $F(7,72)=3.13^{*}$ \\
\hline & 3.1 & $16 \pm 5,69$ & $p<0.05$ & & 0.2 & $13 \pm 5,38$ & ns \\
\hline & 6.25 & $10,8 \pm 3,16$ & ns & & 0.39 & $16,7 \pm 6,96$ & ns \\
\hline & 12.5 & $11 \pm 4,11$ & ns & & 0.78 & $15,5 \pm 6,96$ & $\mathrm{~ns}$ \\
\hline & 50 & $7,8 \pm 4,43$ & ns & & 3.13 & $14,6 \pm 11,70$ & ns \\
\hline & 100 & $9,1 \pm 8,85$ & ns & & 6.25 & $16,3 \pm 12,65$ & $\mathrm{~ns}$ \\
\hline
\end{tabular}

Light Dark in rats. Parameter: Total time in light chamber. Statistical Test: Dunnett's procedure. $N=10$ per group.

\begin{tabular}{|c|c|c|c|c|c|c|c|}
\hline \multirow[t]{4}{*}{ Imepitoin } & C & $25 \pm 12,6$ & $F(4,45)=2.866^{*}$ & Diazepam & C & $18 \pm 10,5$ & $F(4,45)=14,18^{*}$ \\
\hline & 1 & $29,7 \pm 14,29$ & ns & & 1 & $41,9 \pm 17,08$ & $p<0.05$ \\
\hline & 3 & $44,1 \pm 21,82$ & ns & & 3 & $62,7 \pm 31,15$ & $p<0.01$ \\
\hline & 10 & $47,3 \pm 20,02$ & $p<0.05$ & & 6 & $79,3 \pm 27,26$ & $p<0.001$ \\
\hline
\end{tabular}

Light Dark in mice. Parameter: Total time in light chamber. Statistical Test: Dunnett's procedure. $N=10$ per group.

\begin{tabular}{|c|c|c|c|c|c|c|c|}
\hline \multirow[t]{4}{*}{ Imepitoin } & C & $98,8 \pm 21,19$ & $F(3,36)=7,427^{*}$ & Diazepam & C & $87 \pm 19,29$ & $F(3,36)=29,6^{*}$ \\
\hline & 1 & $108 \pm 17,39$ & ns & & 1 & $109 \pm 26,25$ & ns \\
\hline & 3 & $136,5 \pm 24,67$ & $p<0.001$ & & 3 & $133 \pm 39,84$ & $p<0.05$ \\
\hline & 10 & $131 \pm 19,92$ & $p<0.01$ & & 10 & $227,2 \pm 49,96$ & $p<0.0001$ \\
\hline
\end{tabular}

Social Interaction in rats. Parameter: score points. Statistical Test: Kruskal-Wallis with Dunn's post hoc. $N=9$ pairs per group.

\begin{tabular}{lcrccccc}
\hline Imepitoin & $\mathrm{C}$ & $62.89+10,76$ & $H=16.11^{*}$ & Imepitoin & 30 & $60.67+8.68$ & $\mathrm{~ns}$ \\
& 3 & $58+13,26$ & $\mathrm{~ns}$ & Diazepam & 5 & $70.78+8.18$ \\
& 10 & $78.56+13.19$ & $p<0.05$ & & & & $\mathrm{~ns}$
\end{tabular}

Vogel Conflict Test in rats. Parameter: number of shocks received. Statistical Test: Dunnett's procedure. $N=12$ per group.

\begin{tabular}{|c|c|c|c|c|c|c|c|}
\hline \multirow[t]{6}{*}{ Imepitoin } & C & $51,4 \pm 26,67$ & $F(5,66)=9,147^{*}$ & Diazepam & C & $62,3 \pm 22,35$ & $F(3,44)=6,08^{*}$ \\
\hline & 1 & $61,3 \pm 30,14$ & ns & & 0.3 & $70,9 \pm 23,73$ & ns \\
\hline & 3 & $83,2 \pm 24,94$ & ns & & 1 & $92,1 \pm 11,15$ & $p<0.05$ \\
\hline & 10 & $80 \pm 31,87$ & ns & & 3 & $104 \pm 41,22$ & $p<0.01$ \\
\hline & 30 & $126 \pm 54,39$ & $p<0.0001$ & & & & \\
\hline & 50 & $135 \pm 53,69$ & $p<0.0001$ & & & & \\
\hline
\end{tabular}

(Continued) 
TABLE 1 | Continued

\begin{tabular}{|c|c|c|c|c|c|c|c|}
\hline Treatment & Dose & Measure & Statistical result & Treatment & Dose & Measure & Statistical result \\
\hline Chlordiazepoxide & C & $1,6 \pm 2,26$ & $t=4,078 d f=14$ & Imepitoin & 10 & $2,6 \pm 3,39$ & (ns) \\
\hline \multirow[t]{2}{*}{ Imepitoin } & C & $2,9 \pm 5,37$ & $F(4,35)=0,6268$ & Diazepam & 16 & $5,4 \pm 5,37$ & (ns) \\
\hline & 3 & $4,6 \pm 6,22$ & (ns) & & & & \\
\hline
\end{tabular}

Four Plate Test in mice. Parameter: punished crossings. Statistical Test: Dunnett's procedure. $N=10$ per group.

\begin{tabular}{|c|c|c|c|c|c|c|c|}
\hline \multirow[t]{7}{*}{ Imepitoin } & C & $14.7 \pm 4.74$ & $F(7,72)=0.99$ & Diazepam & C & $14.8 \pm 7.91$ & $F(7,72)=3.4^{*}$ \\
\hline & 3.13 & $16.1 \pm 6.01$ & (ns) & & 0.2 & $23.1 \pm 14.23$ & ns \\
\hline & 6.25 & $17.1 \pm 8.22$ & (ns) & & 0.39 & $27.1 \pm 12.65$ & $p<0.05$ \\
\hline & 12.5 & $14.9 \pm 7.59$ & (ns) & & 0.78 & $25.7 \pm 8.22$ & ns \\
\hline & 25 & $14.0 \pm 7.27$ & (ns) & & 1.56 & $27.7 \pm 7.91$ & $p<0.05$ \\
\hline & 50 & $16.6 \pm 13.28$ & (ns) & & 3.13 & $28.2 \pm 15.50$ & $p<0.05$ \\
\hline & 100 & $13.9 \pm 8.22$ & (ns) & & 6.25 & $14.7 \pm 7.59$ & ns \\
\hline
\end{tabular}

Dosage "C" indicates placebo control. All measures presented as mean \pm SD. For ANOVA procedures $F(d F n, d F d)$ is reported with * indicating significance (i.e., $p<0.05)$. All post hoc tests were performed for differences compared to control. ns, non-significant differences. For Alprazolam $0.1 \mathrm{mg} / \mathrm{kg}$ : As this experiment was only a two group set-up, no ANOVA could be performed. An unpaired $t$-test revealed no significant differences $(t=0.2589$; $d f=18)$.

interaction at $10 \mathrm{mg} / \mathrm{kg}$ compared to placebo (Table 1) but had no significant effect on social interaction at either 3 or $30 \mathrm{mg} / \mathrm{kg}$. Signs of sedation were noted in some rats treated with $30 \mathrm{mg} / \mathrm{kg}$ which may have interfered with social interaction. The positive control, diazepam $5 \mathrm{mg} / \mathrm{kg}$ similarly administered by oral gavage likewise increased social interaction (Figure 3A and Table 1).

\section{Conflict-Based Tests in Rodents}

The anxiolytic effect of oral imepitoin $(1,3,10,30$, and $50 \mathrm{mg} / \mathrm{kg})$, diazepam $(0.3,1$, and $3 \mathrm{mg} / \mathrm{kg})$, or placebo in rats was also investigated using the Vogel conflict test. Imepitoin exerted a dose dependent increase in the number of shocks received, which was significantly increased at doses of 30 and $50 \mathrm{mg} / \mathrm{kg}$ compared to placebo (Figure 3B and Table 1). The number of shocks was also increased for diazepam in a dose-dependent manner being significant at doses of 1 and $3 \mathrm{mg} / \mathrm{kg}$ (Table $\mathbf{1}$ ).

Imepitoin (3, 10, and $30 \mathrm{mg} / \mathrm{kg}$ as oral suspension, administered $2 \mathrm{~h}$ before the test) was also tested in the Geller conflict test in rats ( $n=8$ in cross over design), with chlordiazepoxide (16 $\mathrm{mg} / \mathrm{kg}$ p.o. $1 \mathrm{~h}$ prior to test), diazepam (16 mg/kg p.o., $2 \mathrm{~h}$ prior to test) and placebo for comparison.

After administration of $3 \mathrm{mg} / \mathrm{kg}$ imepitoin or $16 \mathrm{mg} / \mathrm{kg}$ diazepam tended to increase the number of punished responses, however, the difference did not reach statistical significance compared to placebo. No effects were observed for 10 and $30 \mathrm{mg} / \mathrm{kg}$ imepitoin. In this study, only chlordiazepoxide after administration of a dose exerting sedative effects $(16 \mathrm{mg} / \mathrm{kg})$ significantly increased the number of punished responses and the number of shocks received (Figure 3C and Table 1). Imepitoin
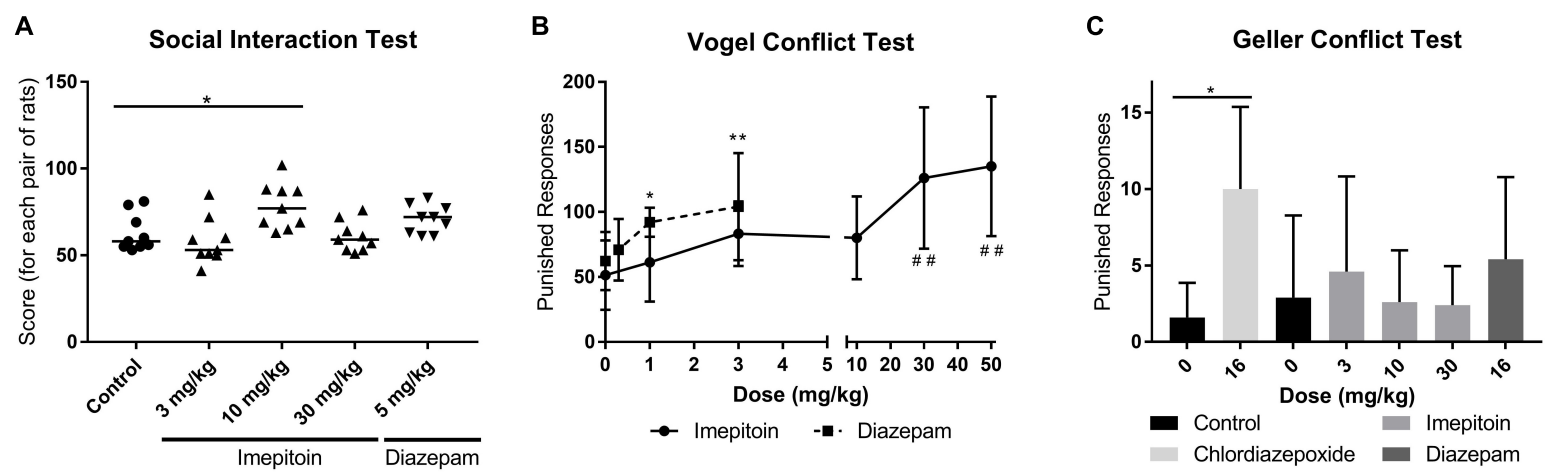

FIGURE 3 | (A) Treatment with $10 \mathrm{mg} / \mathrm{kg}$ imepitoin significantly increased the interaction between pairs of rats ( $n=9$ pairs per group). (B) An increase in the number of punished responses in the Vogel conflict test was observed in doses above $10 \mathrm{mg} / \mathrm{kg}$ imepitoin or above $1 \mathrm{mg} / \mathrm{kg}$ diazepam (Series of three experiments, $n=12$ per group). (C) No relevant effect was observed in the Geller conflict test neither for imepitoin nor for diazepam ( $n=8$ in cross over design). For all tests: mean \pm SD. Comparison against respective control using ANOVA with Dunnett's post hoc.* or \# $p<0.05$; ** or \#\# $p<0.01$ In display B, the symbol "\#" indicates imepitoin and "*" indicates diazepam. 
did not affect the number of unpunished responses at any dose tested, i.e., the substance did not show sedative effects.

In mice, the four plate test was used with intraperitoneal administration of imepitoin $(3.13,6.25,12.5,25,50,100$, and $200 \mathrm{mg} / \mathrm{kg})$, diazepam $(0.2,0.39,0.78,1.56,3.13,6.25$, and $12.5 \mathrm{mg} / \mathrm{kg}$ ), and placebo administered $30 \mathrm{~min}$ before the test. No effect on punished as well as on un-punished behavior was shown for imepitoin (3.13-200 mg/kg i.p), whereas diazepam (0.39-3.13 mg/kg i.p) significantly increased crossings of punished plates compared to placebo (Table 1). In higher doses, diazepam elicited sedative effects.

\section{Noise-Induced Model of Fear and Anxiety in Dogs}

Dogs $(n=24)$ were tested in an open field sound-induced fear model with exposure to artificial stimuli (thunderstorm sound) as eliciting context and treated with a single dose of imepitoin (20 mg/kg p.o.) $138 \mathrm{~min}$ before thunder exposure. Overall, imepitoin significantly lowered the cortisol levels in 13 out of 16 dogs $(81 \%)$ that were declared as cortisol responders at the beginning of the study (Figure 4A). Both during the complete testing period as well as during the thunder interval (minutes 4-6), total distance traveled was significantly higher during the treatment thunder test compared to the baseline thunder test (Figure 5 and Table 2). In addition, total inactivity frequency was significantly higher at treatment than baseline.

Separating the dogs into hypoactive (i.e., those who reacted at baseline with less activity in response to thunder noise) and hyperactive (i.e., those who reacted at baseline with more activity in response to thunder noise), in both groups ( $n=12$ each) an increase in distance traveled and inactivity frequency was observed. However, the effect was larger for the hypoactive dogs and was significant in this subgroup only (distance traveled: $p<0.001$ in paired $t$-test; inactivity frequency: $p<0.05$ ).
In contrast, in a separate experiment dogs $(n=25)$ treated with dexmedetomidine applied as oromucosal gel showed a significantly decreased total distance traveled (Figure 5 and Table 2). Dexmedetomidine showed no relevant effect on cortisol levels in dogs that were declared as cortisol responders at the beginning of the study (Figure 4B and Table 2).

\section{DISCUSSION}

Imepitoin was tested in a battery of standard preclinical tests for anxiety behavior. The observed profile appears typical for anxiolytic drugs (Andrews et al., 2014). Based upon the performance of imepitoin in these standard tests designed to evaluate potential anxiolytic activity, it can be concluded that imepitoin has anxiolytic properties similar to benzodiazepines.

In an in vitro model, imepitoin was capable of preventing the effect of CRF on LC neurons without suppressing the basal activity of these cells, an activity which is suggestive for an anti-stress effect of imepitoin (Valentino et al., 1993).

Ethological test paradigms rely on stimulated forms of anxiety within the normal range. The elevated-plus-maze for example is based on small rodent's avoidance of open, bright areas due to the higher risk of predator attacks (Hogg, 1996; Rodgers et al., 1997). Especially the elevated-plus maze appears to be sensitive to positive GABA modulating agents, while other substance classes like for example $\alpha_{2}$-agonists (e.g., dexmedetomidine) showed no effect in this test (Salonen et al., 1992). The social interaction test reflects the uncertainty in meeting unknown individuals in unfamiliar environments, and this ethologically natural paradigm can be used to examine social avoidance (File and Seth, 2003). In all of the tests applied, imepitoin showed comparable responses to diazepam, however, at higher doses. This observation supports the notion that imepitoin acts as a partial agonist.

In addition, conflict-based tests were used, measuring anxiolytic-like activity as the maintenance of a behavioral

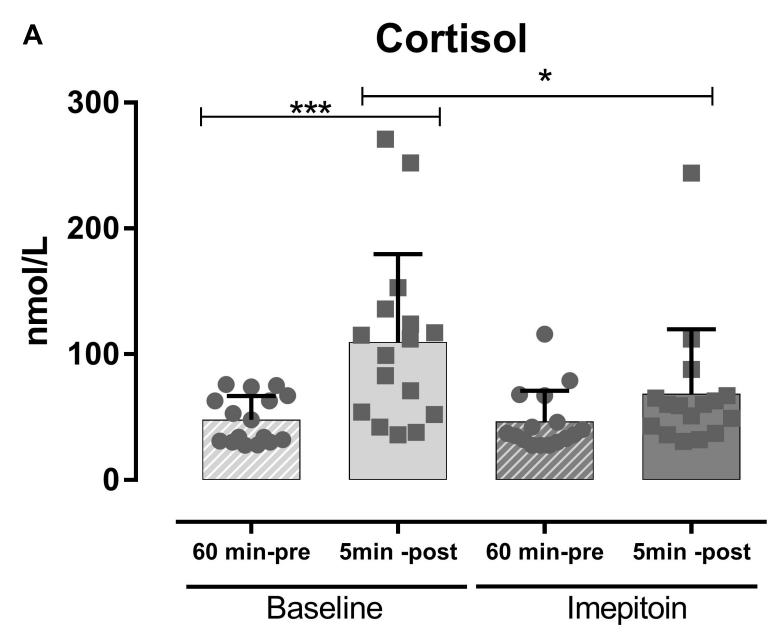

B

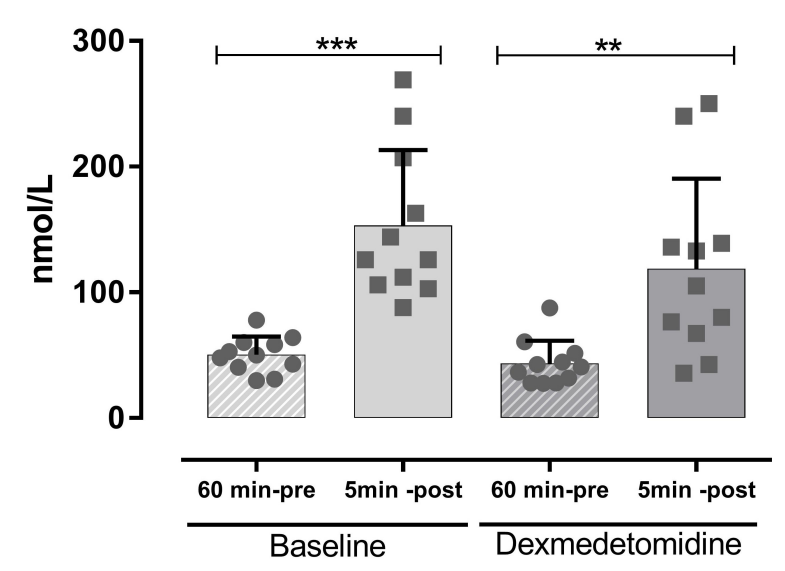

FIGURE 4 | In an open field noise-induced fear model (i.e., exposure to thunderstorm noises) serum cortisol values were measured 60 min before and 5 min after exposure to noise. (A) In a first experiment $(n=12)$, single dose imepitoin treatment (20 mg/ $\mathrm{kg})$ was compared to baseline. (B) The same setup was independently repeated $(n=25)$ with a single dose of dexmedetomidine. Mean $\pm S D ;{ }^{*} p<0.05 ;{ }^{* *} p<0.01$; and ${ }^{* * *} p<0.001$ in ANOVA with Sidak's post hoc. 


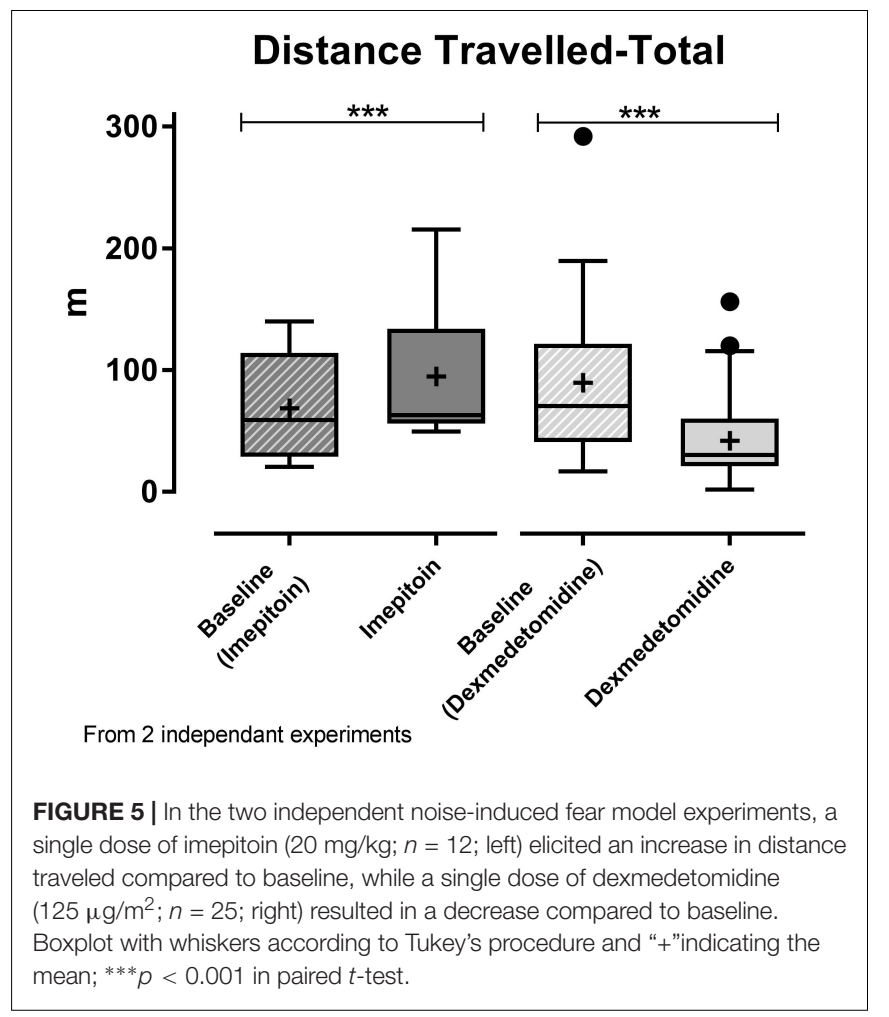

response (for example, licking or bar pressing) despite the receipt of a mild electric shock. Anxiolytic action in these tests is generally defined as maintenance of responding in the presence of the punishing stimulus since this would override the inhibition. Interpretation of the results appears difficult under the premise that disinhibition alone is not per se an anxiolytic action, and analgesic effects of a test compound could produce similar effects simply by inhibiting pain reactions to the punishment (Andrews et al., 2014). In the Geller conflict test a large variability in response to certain benzodiazepines is described in the literature (Babbini et al., 1982). Regardless, conflict situations with two opposing impulses are a component of anxiety disorders, and conflict based tests are still widely applied to screen for anxiolytic drug candidates. Imepitoin showed only a significant effect in the Vogel conflict test, but not in the Geller conflict test or the four plate test. Apparently imepitoin has no strong disinhibition component and does not result in irrational risk taking.

We observed anxiolytic activity also in dogs in a provoked open field sound-induced fear model, where reactions to noises were elicited by a sound recording of thunderstorms. While tests like these are considered to have a good test-retest reliability, the generalizability to patients relating to changes in locomotion and exploratory behavior observed under anxiolytic treatment underlies the general limitations of a model (Wormald et al., 2016). We observed an increase in locomotion measured in distance traveled after imepitoin treatment. In addition, dogs paused their activity more often under treatment, which might indicate an interruption of their current behavior to assess their environment (McNaughton and Gray, 2000). After dexmedetomidine treatment, which was shown to have anxiolytic

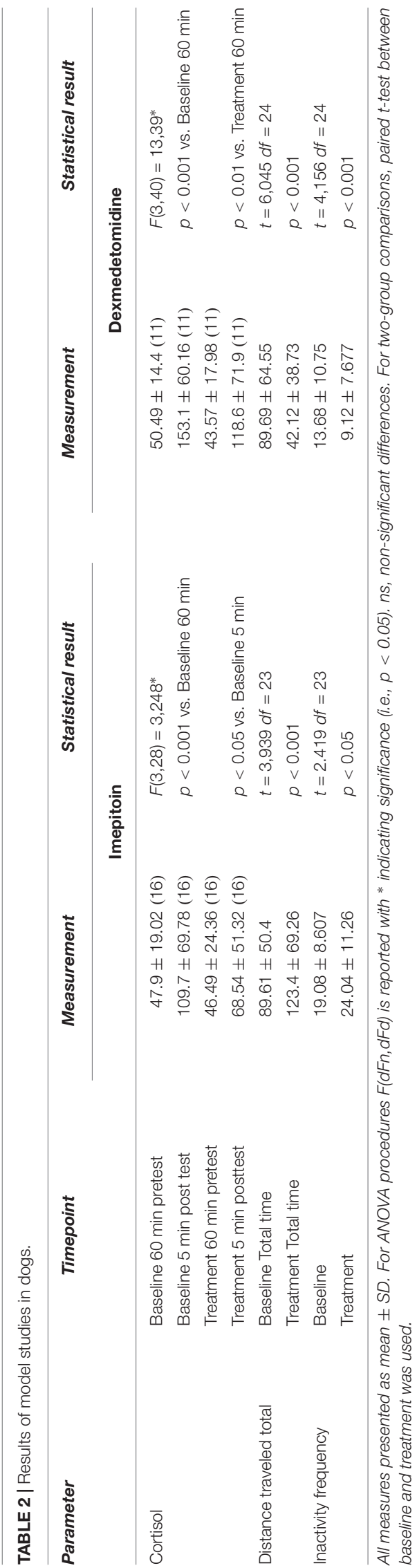


effects in dogs (Korpivaara et al., 2017), we observed a decrease in locomotion. This is not a surprising result as dexmedetomidine, and other $\alpha 2$-adrenoceptor agonists, are widely used as premedication to induce anesthesia (Beckman, 2013) and sedative effects were already described for transmucosal administration in dogs (Cohen and Bennett, 2015). For comparison, the effect of benzodiazepines in this model is associated with an increase in exploratory behavior, which is also measured as increase in total distance traveled (Wormald et al., 2016). Due to the highly controlled conditions, the changes in behavior in the imepitoin or dexmedetomidine groups compared to baseline are most plausibly explained by the treatment.

Cortisol as a stress hormone indicative of arousal plays a role in anxiety disorders. For example, dogs with noise phobia suffer from severe mental stress evidenced by an inability to relax and cortisol levels in these dogs increasing more than twofold during thunderstorms (Dreschel and Granger, 2005). In addition, dogs with noise phobia have higher cortisol levels in their hair (Siniscalchi et al., 2013). In our hands, we observed an ameliorating effect of imepitoin on cortisol levels in response to thunderstorm noises, but not for dexmedetomidine. Benzodiazepines were found to suppress cortisol levels (Manthey et al., 2010), and thus these findings further support the benzodiazepine-like anxiolytic effect of imepitoin.

A relevant limitation of the suite of studies presented here is the use of different dosages and administration routes across studies. While the different dosages were chosen based on the stage of the development program reported here, it complicates comparison between the models and allows no definitive conclusions on the optimal dose. Notably, the logistical need for separate independent experiments due to the large number of groups limits the comparison between treatments and between independent experiments to a qualitative assessment. In addition, the conclusion of an anxiolytic effect is based on the similar performance to benzodiazepines in standard models of anxiety, which needs validation in clinical trials.

In all animal models the imepitoin doses needed for an anxiolytic effect were not associated with sedation. In rodents, there was at least a factor of 10 between anxiolytic doses and doses with mild signs of sedation. In the dog model, treatment with imepitoin resulted in increased locomotion.

\section{REFERENCES}

Andrews, N. A., Papakoste, M., and Barmes, N. M. (2014). Discovery of novel anxiolytic agents - The trials and tribulations of pre-clinical models of anxiety. Neurobiol. Dis. 61, 72-78. doi: 10.1016/j.nbd.2013.10.006

Araujo, J. A., De Rivera, C., Landsberg, G. M., Adams, P. E., and Milgram, N. W. (2013). Development and validation of a novel laboratory model of soundinduced fear and anxiety in Beagle dogs. J. Vet. Behav. Clin. Appl. Res. 8, 204-212. doi: 10.1016/j.jveb.2012.10.008

Babbini, M., Gaiardi, M., and Bartoletti, M. (1982). Benzodiazepine effects upon geller-seifter conflict test in rats: analysis of individual variability. Pharmacol. Biochem. Behav. 17, 43-48. doi: 10.1016/0091-3057(82) 90260-X

Beckman, B. (2013). Anesthesia and pain management for small animals. Vet. Clin. North Am. 43, 669-688. doi: 10.1016/j.cvsm.2013.02.006

\section{CONCLUSION}

In conclusion, imepitoin showed anxiolytic properties similar to benzodiazepines in various standard models for anxiety behavior but without producing the known adverse reactions of benzodiazepines such as sedation, without evidence of behavioral inhibition in the situations explored. Accordingly imepitoin appears to be a promising candidate for treating anxiety disorders, and first data in dogs with anxiety problems showed promising results for therapeutic use of imepitoin in canine anxiety disorders (McPeake and Mills, 2017).

\section{AVAILABILITY OF DATA AND MATERIAL}

The raw data supporting the conclusions of this manuscript will be made available by the authors, without undue reservation, to any qualified researcher.

\section{AUTHOR CONTRIBUTIONS}

All authors had access to all the study information, raw data, and approved the manuscript. CR led the conduct and evaluation of rodent models. DM, OE, GL, and AM contributed to the conception, design of the dog anxiety model, and the interpretation of the results. $\mathrm{AM}$ and $\mathrm{MB}$ conducted and evaluated the dog open field studies. OE prepared the manuscript with support of all authors.

\section{FUNDING}

The study was funded by Boehringer Ingelheim Vetmedica $\mathrm{GmbH}$.

\section{SUPPLEMENTARY MATERIAL}

The Supplementary Material for this article can be found online at: https://www.frontiersin.org/articles/10.3389/fphar. 2018.01225/full\#supplementary-material

Bourin, M., and Hascoet, M. (2003). The mouse light/dark box test. Eur. J. Pharmacol. 463, 55-65. doi: 10.1016/S0014-2999(03)01274-3

Cohen, A. E., and Bennett, S. L. (2015). Oral transmucosal administration of dexmedetomidine for sedation in 4 dogs. Can. Vet. J. 56, 1144-1148.

Dreschel, N. A., and Granger, D. A. (2005). Physiological and behavioral reactivity to stress in thunderstorm-phobic dogs and their caregivers. Appl. Anim. Behav. Sci. 95, 153-168. doi: 10.1016/j.physbeh.2017.04.008

File, S. E., and Hyde, J. R. (1978). Can social interaction be used to measure anxiety? Br. J. Pharmacol. 62, 19-24.

File, S. E., and Seth, P. (2003). A review of 25 years of the social interaction test. Eur. J. Pharmacol. 463, 35-53. doi: 10.1016/S0014-2999(03) 01273-1

Geller, I., and Seifter, J. (1960). The effects of meprobamate, barbiturates, d-amphetamine and promazine on experimentally induced conflict in the rat. Psychopharmacologia 1, 482-492. doi: 10.1007/BF00429273 
Griebel, G., and Holmes, A. (2013). 50 years of hurdles and hope in anxiolytic drug discovery. Nat. Rev. Drug Discov. 12, 667-687. doi: 10.1038/nrd4075

Hogg, S. (1996). A review of the validity and variability of the elevated plusmaze as an animal model of anxiety. Pharmacol. Biochem. Behav. 54, 21-30. doi: 10.1016/0091-3057(95)02126-4

Jones, G. H., Schneider, C., Schneider, H. H., Seidler, J., Cole, B. J., and Stephens, D. N. (1994). Comparison of several benzodiazepine receptor ligands in two models of anxiolytic activity in the mouse: an analysis based on fractional receptor occupancies. Psychopharmacology 114, 191-199. doi: 10. 1007/BF02244836

Korpivaara, M., Laapas, K., Huhtinen, M., Schöning, B., and Overall, K. (2017). Dexmedetomidine oromucosal gel for noiseassociated acute anxiety and fear in dogs-a randomised, double-blind, placebo-controlled clinical study. Vet. Rec. 180:356. doi: 10.1136/vr.104045

Liss, B., Bruns, R., and Roeper, J. (1999). Alternative sulfonylurea receptor expression defines metabolic sensitivity of K-ATP channels in dopaminergic midbrain neurons. EMBO J. 18, 833-846. doi: 10.1093/emboj/18.4.833

Löw, K., Crestani, F., Kleist, R., Benke, D., Brünig, I., Benson, J. A., et al. (2000). Molecular and neuronal substrate for the selective attenuation of anxiety. Sci. Prog. 290, 131-134.

Manthey, L., Giltay, E. J., Van Veen, T., Neven, A. K., Vreeburg, S. A., Penninx, B. W., et al. (2010). Long-term benzodiazepine use and salivary cortisol: the Netherlands Study of Depression and Anxiety (NESDA). J. Clin. Psychopharmacol. 30, 160-168. doi: 10.1097/JCP.0b013e3181d41f41

McNaughton, N., and Gray, J. A. (2000). Anxiolytic action on the behavioural inhibition system implies multiple types of arousal contribute to anxiety. J. Affect. Disord. 61, 161-176. doi: 10.1016/S0165-0327(00)00344-X

McPeake, K. J., and Mills, D. S. (2017). The use of imepitoin (Pexion) on fear and anxiety related problems in dogs - a case series. BMC Vet. Res. 13:173. doi: 10.1186/s12917-017-1098-0

Millan, M. J., and Brocco, M. (2003). The Vogel conflict test: procedural aspects, gamma-aminobutyric acid, glutamate and monoamines. Eur. J. Pharmacol. 463, 67-96. doi: 10.1016/S0014-2999(03)01275-5

Rodgers, R. J., Cao, B.-J., Dalvi, A., and Holmes, A. (1997). Animal models of anxiety: an ethological perspective. Braz. J. Med. Biol. Res. 30, 289-304. doi: 10.1590/S0100-879X1997000300002

Rundfeldt, C., Gasparic, A., and Wlaz, P. (2014). Imepitoin as novel treatment option for canine idiopathic epilepsy: pharmacokinetics, distribution, and metabolism in dogs. J. Vet. Pharmacol. Ther. 37, 421-434. doi: 10.1111/jvp. 12117

Rundfeldt, C., and Loscher, W. (2014). The pharmacology of imepitoin: the first partial benzodiazepine receptor agonist developed for the treatment of epilepsy. CNS Drugs 28, 29-43. doi: 10.1007/s40263-013-0129-z
Salonen, M., Onaivi, E. S., and Maze, M. (1992). Dexmedetomidine synergism with midazolam in the elevated plus-maze test in rats. Psychopharmacology 108, 229-234. doi: 10.1007/BF02245313

Sigel, E., Baur, R., Netzer, R., and Rundfeldt, C. (1998). The antiepileptic drug AWD 131-138 stimulates different recombinant isoforms of the rat GABA(A) receptor through the benzodiazepine binding site. Neurosci. Lett. 245, 85-88. doi: 10.1016/S0304-3940(98)00186-4

Siniscalchi, M., Mcfarlane, J. R., Kauter, K. G., Quaranta, A., and Rogers, L. J. (2013). Cortisol levels in hair reflect behavioural reactivity of dogs to acoustic stimuli. Res. Vet. Sci. 94, 49-54. doi: 10.1016/j.rvsc.2012.02.017

Skolnick, P. (2012). Anxioselective anxiolytics: on a quest for the Holy Grail. Trends Pharmacol. Sci. 33, 611-620. doi: 10.1016/j.tips.2012.08.003

Stein, M. B., and Steckler, T. (2010). Behavioral Neurobiology of Anxiety and Its Treatment. Heidelberg: Springer. doi: 10.1007/978-3-642-02912-7

Valentino, R. J., Foote, S. L., and Page, M. E. (1993). The Locus Coeruleus as a Site for integrating corticotropin-releasing factor and noradrenergic mediation of stress responsesa. Ann. N. Y. Acad. Sci. 697, 173-188. doi: 10.1111/j.1749-6632. 1993.tb49931.x

Walf, A. A., and Frye, C. A. (2007). The use of the elevated plus maze as an assay of anxiety-related behavior in rodents. Nat. Protoc. 2, 322-328. doi: 10.1038/nprot. 2007.44

Whiting, P. J. (2006). GABA-A receptors: a viable target for novel anxiolytics? Curr. Opin. Pharmacol. 6, 24-29. doi: 10.1016/j.coph.2005.08.005

Wormald, D., Lawrence, A. J., Carter, G., and Fisher, A. D. (2016). Validation of modified open field behaviour as a measure of trait anxiety in the dog. Appl. Anim. Behav. Sci. 179, 95-102. doi: 10.1016/j.applanim.2016.03.004

Conflict of Interest Statement: This publication followed the GPP3 guidelines. $\mathrm{OE}$ is an employee of Boehringer Ingelheim Vetmedica GmbH, Germany, the marketing authorization holder of Pexion ${ }^{\circledR}$, containing Imepitoin as active principle. CR and DM acted as consultants for Boehringer Ingelheim.

The remaining authors declare that the research was conducted in the absence of any commercial or financial relationships that could be construed as a potential conflict of interest.

Copyright (C) 2018 Engel, Masic, Landsberg, Brooks, Mills and Rundfeldt. This is an open-access article distributed under the terms of the Creative Commons Attribution License (CC BY). The use, distribution or reproduction in other forums is permitted, provided the original author(s) and the copyright owner(s) are credited and that the original publication in this journal is cited, in accordance with accepted academic practice. No use, distribution or reproduction is permitted which does not comply with these terms. 